\title{
Effects of five southern California macroalgal diets on consumption, growth, and gonad weight, in the purple sea urchin Strongylocentrotus purpuratus
}

Matthew C Foster, Jarrett E Byrnes, Daniel C Reed

Consumer growth and reproductive capacity are direct functions of diet. Strongylocentrotid sea urchins, the dominant herbivores in California kelp forests, strongly prefer giant kelp (Macrocystis pyrifera), but are highly catholic in their ability to consume other species. The biomass of Macrocystis fluctuates greatly in space and time and the extent to which urchins can use alternate species of algae or a mixed diet of multiple algal species to maintain fitness when giant kelp is unavailable is unknown. We experimentally examined the effects of single and mixed species diets on consumption, growth and gonad weight in the purple sea urchin Strongylocentrotus purpuratus. Urchins were fed single species diets consisting of one of four common species of macroalgae (the kelps Macrocystis pyrifera and Pterygophora californica, and the red algae Chondracanthus corymbiferus and Rhodymenia californica (hereafter referred to by genus) or a mixed diet containing all four species ad libitum over a 13-week period in a controlled laboratory setting. Urchins fed Chondracanthus, Macrocystis and a mixed diet showed the highest growth (in terms of test diameter, wet weight and jaw length) and gonad weight while urchins fed Pterygophora and Rhodymenia showed the lowest. Urchins consumed their preferred food, Macrocystis at the highest rate when offered a mixture, but consumed Chondracanthus or Macrocystis at similar rates when the two algae were offered alone. The differences in urchin feeding behavior and growth observed between these diet types suggest the relative availability of the algae tested here could affect urchin populations and their interactions with the algal assemblage. The fact that the performance of urchins fed Chondracanthus was similar or higher than those fed the preferred Macrocystis suggests that the availability of the former could could sustain growth and reproduction of purple sea urchins during times of low Macrocystis abundance as is common following large wave events. 


\section{Effects of five southern California macroalgal diets on consumption, growth}

\section{2 and gonad weight in the purple sea urchin Strongylocentrotus purpuratus}

3 Matthew C. Foster ${ }^{1 *}$, Jarrett E. K. Byrnes ${ }^{1,2}$, Daniel C. Reed ${ }^{1}$

41 - Marine Science Institute, University of California Santa Barbara, Santa Barbara, CA 93106

52 -Department of Biology, University of Massachusetts Boston, Boston, MA 02125

$6 \quad *$-Corresponding author

7 Email: mcf543@gmail.com

\section{Introduction}

Sea urchins are dominant grazers in many benthic marine systems around the world and

11 can exert a strong top-down influence on community structure (Lawrence 1975). In kelp forests

12 along the west coast of North America strongylocentrotid sea urchins can have a large effect on

13 the standing biomass of the giant kelp Macrocystis pyrifera and understory algal species (North

14 \& Pearse 1970; Leighton 1971; Dayton 1985). The standing biomass of giant kelp, a preferred

15 food of sea urchins (Leighton 1971), fluctuates greatly in response to a range of physical and

16 biological processes (Dayton et al. 1999; Reed, Rassweiler \& Arkema 2008; Reed et al. 2011,

17 Cavanaugh et al. 2011), and when its abundance is low sea urchins are known to shift their diet to

18 consume the remaining algal assemblage (Ebeling, Laur \& Rowley 1985; Harrold \& Reed 1985).

19 Increased knowledge of diet's effects on sea urchin consumption, growth and reproduction should

20 lead to a better understanding of when and where they can have strong ecosystem effects.

21 The feeding rates, food selectivity, growth and reproduction of a variety of species of sea

22 urchins vary with changes in quantity and types of available foods. This variation is due to

23 consumer food preferences and the digestibility, absorption efficiency and composition of

24 available food (Lawrence 1975). Feeding and nutrient allocation to somatic and gonadal growth 
25 and gametogenesis also vary with diet, time of year, and environmental conditions (Lawrence \&

26 Lane 1982). Some species of sea urchins exhibit strong food preferences in the presence of a

27 mixture of algae (Leighton 1968). Many perform better when consuming mixed diets

28 (Beddingfield \& McClintock 1997; Fernandez \& Boudouresque 1998; Fernandez \& Pergent

29 1998; Vadas et al. 2000), suggesting that algal assemblage diversity could affect sea urchin

30 performance. A comprehensive understanding of the interactions between sea urchins and

31 macroalgal assemblages in any system requires knowledge of the factors that affect sea urchin

32 feeding behavior, and performance.

34 gonad weight of the purple sea urchin Strongylocentrotus pupuratus using four co-occurring

35 species of macroalgae known to be part of its diet: the kelps Macrocystis pyrifera and

36 Pterygophora californica, and the red algae Chondracanthus corymbiferus and Rhodymenia

37 californica (all algal species hereafter referred to by genus). These four species were chosen

38 because they represented a large proportion ( $>75 \%)$ of the algal biomass in our study region in

39 southern California (Miller, Harrer \& Reed 2012) and are consumed by purple sea urchins in the

40 field (Byrnes, Cardinale \& Reed 2013). Thus, changes in the performance of purple sea urchins

41 resulting from changes in the availability of these four species of macroalgae could have large

42 implications for the structure of subtidal reef communities.

43 Methods

44 We measured algal consumption, test growth, jaw growth, change in whole body wet

45 weight and gonad weight of urchins fed one of five experimental diets over an 89-day period in a

46 controlled laboratory setting. Urchins used in the experiment were collected on October 2010

47 from a shallow ( $\sim 4 \mathrm{~m}$ depth) boulder reef $\left(34^{\circ} 24.9 \mathrm{~N} 119^{\circ} 49.8 \mathrm{~W}\right)$ located offshore of the

48 University of California, Santa Barbara. To minimize inherent variation in growth potential, 
consumption potential, and initial gonad weight, urchins were chosen to be relatively uniform in

50 size (horizontal test diameter $33.5 \pm 0.4 \mathrm{~mm}$, mean $\pm \mathrm{SE}$ ) and presumably age (Ebert 1968; Ebert

51 1977; Kenner 1992; Russell 1987), and collected from a denuded urchin barren where their gonad

52 weight was predicted to be uniformly low.

53 Upon collection, urchins were transported to the laboratory in insulated containers, placed

54 in aquaria with running seawater and starved for one week prior to the start of the experiment.

55 Blotted dry urchins (placed with the aboral end facing down on paper towels for 5 minutes) were

56 weighed to the nearest 0.01 gram and their horizontal test diameter was measured to the nearest

$570.1 \mathrm{~mm}$ using Vernier calipers. To measure jaw growth, each urchin was injected with the

58 fluorescent marker tetracycline following Ebert (1982). $1.0 \mathrm{~g}$ of tetracycline was mixed with 100

$59 \mathrm{~mL}$ seawater and $0.2 \mathrm{~mL}$ of the resulting solution was injected into each urchin through the

60 peristomal membrane with a hypodermic needle. Tetracycline binds to actively calcifying tissues,

61 effectively labeling jaw material present at the start of the experiment. Jaw material calcified after

62 tetracycline administration was therefore unlabeled.

63 Each urchin was assigned to one of 35 labeled plastic containers $(32 \times 19 \times 11 \mathrm{~cm})$

64 supplied with flow-through seawater. This setup allowed us to keep track of individuals without

65 the use of external tags. Each container was supplied from the same head water tank, however the

66 containers were not connected and therefore water supplies were independent. Seawater

67 temperatures ranged from 11.6 to $16.3{ }^{\circ} \mathrm{C}$ during the experiment and matched ambient conditions.

68 Urchins were fed one of five macroalgal diets: a monospecific diet of either Macrocystis pyrifera,

69 Pterygophora californica, Rhodymenia californica, or Chondracanthus corymbiferus, or an equal

70 mixture of all four species (hereafter referred to as a mixed diet) with $n=7$ urchins per diet type.

71 Sea urchin containers assigned to each treatment were spread out randomly in space. Algae were

72 added to the tanks during nine periods ranging in length from 4 to 8 days in which all

73 experimental urchins were given a known amount of algae (on average either $34 \mathrm{~g}$ of one species, 
$74 \mathrm{~g}$ in the mixed diet treatment $10 \mathrm{~g}$ of each of the four species). Sea urchins were given more

75 algae than they consumed in all cases, except during one feeding period in which urchins in

76 mixed diet treatments consumed all Macrocystis approximately 48 hours before algae was

77 removed and the feeding period terminated. During the 89-day experiment, urchins were exposed

78 to algae for approximately 54 days. Rhodymenia was absent from the monospecific Rhodymenia

79 treatment and from the mixed diet treatment for one of the feeding periods $(14 \%$ of the total

80 exposure time) due to its lack of availability in the field. Feeding periods were kept relatively

81 short to prevent degradation of the algae, and algae were not immediately replaced due to

82 logistical constraints on field collections. To study algal consumption, algal wet weight (after

83 removing excess water with a spinning colander) was measured at the beginning and end of each

84 feeding period. Consumption was calculated as wet weight (g) of algae consumed per urchin per

85 hour using the total amount of hours urchins were exposed to algae (exposure time). We used

86 consumption rate rather than amount consumed to standardize for different exposure times in the

87 Rhodymenia treatment. To evaluate the nutritional content of the algae, tissue samples of each

88 species of algae were collected at three time points during the experiment and analyzed for

89 carbon and nitrogen content (\% dry weight). Samples were weighed wet (after removing excess

90 water with a spinning colander), placed in a drying oven at $60{ }^{\circ} \mathrm{C}$ until dry, ground to a fine

91 powder, and stored in a desiccator until analyzed by the UCSB Marine Science Institute

92 Analytical Laboratory using the Dumas combustion method (duplicate samples from each species

93 at each time point were tested). Mean carbon:nitrogen $(\mathrm{C}: \mathrm{N})$ ratios were calculated for each algal

94 species and linear models were fit for each measure of urchin performance (see below) using C:N

95 as the independent variable in each case.

96 At the end of the experiment the horizontal test diameter and wet weight (measured to the

97 nearest $0.01 \mathrm{~g}$ in blotted dry urchins) of each urchin was measured. The change in test diameter

98 and change in wet weight of each individual over the experiment was calculated by subtracting 
99 the initial value measured at the beginning of the experiment from that measured at the end of the

100 experiment. Gonads were removed from each urchin upon dissection, placed in an oven at $60^{\circ} \mathrm{C}$

101 until dry and weighed to the nearest $0.01 \mathrm{~g}$. Final gonad dry weight was used as a measure of

102 gonad growth because initial gonad weight was presumed to be nil as all individuals used in the

103 experiment were similar in size and collected from a barren. We verified this assumption by

104 taking eight urchins (test diameter $34.3 \pm 1.0 \mathrm{~mm}$ (mean $\pm \mathrm{SE}$ )) from the original collection site

105 in the middle of the experiment (inadvertently, no data from the source population were taken at

106 the beginning of the experiment) and measuring the mass of their gonads (see Results) following

107 the same procedure described above.

108 Jaw growth was measured using half-pyramids of the aristotle's lantern following Ebert

109 (1982). Half pyramids were removed from each urchin and soaked in a 5\% sodium hypochlorite

110 solution for 24 hours. For one half-pyramid per urchin, the total length from the oral tip to the flat

111 shoulder at the aboral end (see Ebert (1980a) for pictures of points of measurement) was

112 measured to the nearest $0.01 \mathrm{~mm}$ using a dissecting microscope equipped with an ultraviolet lamp

113 and an ocular micrometer. Fluorescence from labeled tetracycline was observed from the oral tip

114 to part way up the length of the jaw, indicating that this material had been present at the start of

115 the experiment. Jaw growth was measured as the length of the non-fluorescent "band" extending

116 from the top of the fluorescent area to the flat shoulder at the aboral end.

117 Differences among treatments were analyzed separately for each response variable

118 (consumption rate ( $\mathrm{g}$ of algae consumed $\cdot \mathrm{h}^{-1}$ averaged over the experiment), change in test

119 diameter, change in jaw length, change in whole body wet weight, and final gonad dry weight)

120 using one-way ANOVA. Diet selectivity was studied by examining the rate at which individual

121 species of algae were consumed in mixture treatments by fitting a linear model with algal species

122 as a fixed effect and container (individual urchin enclosure) included as a random effect (Gelman

$123 \&$ Hill 2006) as consumption rates of individual species of algae in a single container were not 


\section{PeerJ Reviewing Manuscript}

124 independent. After fitting linear models, assumptions of normality were tested by performing the

125 Shapiro-Wilk test on the linear regression residuals, and homogeneity of variance was tested

126 using Bartlett's test on the residuals across treatments (or across algal species, in the case of the

127 mixed model). Homogeneity of varianace was not supported for the linear models of change in

128 wet weight, consumption across treatments, and consumption within the mixed diet. $(\mathrm{p}<0.05)$.

129 Given that our data were from consumption and growth processes (implying multiplicative error)

130 these three models were re-fit with log base 10 transformed data, and the resulting regression

131 residuals exhibited normality and homogeneity of variance $(\mathrm{p}>0.05)$. A post-hoc Tukey test was

132 used to compare means (with statistical significance determined at the $\mathrm{p}<0.05$ level)—False

133 Discovery Rate corrected p-values (Benjamini \& Hochberg 2000) were used in the case of the

134 mixed model. For the log-transformed data, least-squares means and standard errors were back-

135 transformed for plotting purposes. All statistical models were fit using R version 2.15-3 ( $\mathrm{R}$

136 Development Core Team 2012) with the nlme package for mixed models (Pinhero et al. 2012)

137 and the multcomp library for post-hoc analyses (Hothorn et al 2008).

138

139 Results

140 Diet type had a significant effect on all performance measures (Table 1). Sea urchins fed

141 Chondracanthus, Macrocystis and mixed diets exhibited the highest test growth, jaw growth, wet

142 weight gain, and gonad weight, with no significant differences between these three diets (Figure

143 1). Urchins fed Pterygophora exhibited significantly lower test growth compared to those fed

144 Chondracanthus and Macrocystis diets, but had jaw growth and gonad weight that were not

145 statistically different from either of them (Figure 1). Urchins fed Rhodymenia exhibited the

146 lowest values of all growth metrics and gonad weight (except that urchins fed Pterygophora had

147 slightly lower mean test growth), with values significantly lower than those of urchins fed 
148 Chondracanthus, Macrocystis and mixed diets, in most cases (Figure 1). Urchins collected from

149 the field as a control group in the middle of the experiment had a gonad weight of $0.20 \pm 0.06 \mathrm{~g}$

$150($ mean $\pm \mathrm{SE})$ which was statistically not detectably different $(\mathrm{p}=0.24$, Welch two-sample t-test-

151 the assumption of normality was met for both samples (Shapiro-Wilk p > 0.05) — from the gonad

152 weight of experimental urchins fed Rhodymenia, the least nutritious diet (Figure 1c).

153 Within the mixed diet, sea urchins consumed Macrocystis at the highest rate, over twice as

154 fast as any other species (Figure 2a, Table 2). When algae were offered alone, however, the

155 consumption rate of Chondracanthus and the mixed diet were similar to that of Macrocystis

156 (Figure 2b). In contrast, urchins consumed Pterygophora and Rhodymenia offered singly at the

157 lowest rates.

158 The four species of algae used in the experiment differed in nutritional value as

159 determined by their C:N ratios (Figure 3). Importantly, we found no relationship between an

160 alga's $\mathrm{C}: \mathrm{N}$ ratio and food quality as measured by urchin performance $(\mathrm{p}>0.27$ for all

161 correlations between the various measures of urchin performance and algal C:N ratio), with the

162 exception of a correlation between gonad weight and algal $\mathrm{C}: \mathrm{N}$ ratio (slope $=0.04 \pm 0.02$

163 (estimate $\pm \mathrm{SE}), \mathrm{p}=0.01$ ). Counter to expectations, the species with the lowest $\mathrm{C}: \mathrm{N}$ ratio (and

164 thus the highest expected nutritional value) was Rhodymenia, which proved to be the least

165 nutritional to urchins in terms of somatic and gonadal growth.

\section{Discussion}

We found test growth, wet weight gain, jaw growth, and gonad weight varied significantly among purple sea urchins as a function of diet. Overall, urchins fed monospecific diets of

170 Chondracanthus, Macrocystis, and those fed a mixed diet grew significantly faster than those that

171 were fed monospecific diets of Pterygophora or Rhodymenia, while urchins fed Rhodymenia had 
172 the lowest gonad weights. Urchins showed a strong preference for the naturally abundant

173 Macrocystis, even when other algae were offered alongside. Our results suggest, however, that a

174 diet consisting of other less preferred species of algae can sustain S. purpuratus at equally high

175 levels of fitness at least over the short-term. This feature may be critically important in

176 maintaining the reproductive capacity of purple sea urchins during the peak winter spawning

177 season when Macrocystis is least abundant due to intensive wave disturbance (Reed, Rassweiler

178 \& Arkema 2008; Reed et al. 2011).

179 Since no differences in performance were observed among urchins fed Chondracanthus,

180 Macrocystis (monospecific) and mixed diets, we found little evidence that purple sea urchins fed

181 a mixed diet benefitted over and above those fed a monospecific diet as long as either

182 Macrocystis or Chondracanthus were present in the mixture. Because our particular mixed diet

183 did not lead to increased performance, there appeared to be no benefit of diet complementarity

184 (as assumed by the balanced diet hypothesis (Pennings, Nadeau \& Paul 1993)). Furthermore,

185 since consumption was not higher in urchins fed a mixed diet, as could be permitted if species-

186 specific toxins limited consumption of any one species, it does not seem likely that toxin

187 minimization played a large role.

188 Despite these results, Macrocystis was consumed at the highest rate in mixed diets,

189 suggesting that the effects of a mixed diet in the absence of this preferred food might prove

190 different. Understanding urchin performance from algal mixtures in the absence of Macrocystis

191 would be useful for understanding urchin dynamics after major kelp removal, as is common

192 following large wave events. In this framework, Byrnes, Cardinale \& Reed (2013) found that

193 reduction in the abundance of sessile species by grazing purple sea urchins was positively

194 correlated with species richness in plots where Macrocystis had been removed.

195 The low values for growth and gonad weight observed in purple sea urchins that were fed 196 a monospecific diet of Rhodymenia occurred in spite of the fact that this species was often 
covered with epiphytic invertebrates such as hydroids and encrusting bryozoans, which have been

198 shown to increase urchin somatic and gonad growth (Knip \& Scheibling 2007 and references

199 therein). The fact that this alga was absent from the Rhodymenia monospeicifc diet and mixed

200 diet for $14 \%$ of the total exposure time (due to low availability for collection) most likely did not

201 bias results of performance measurements by much; test growth, jaw growth, change in wet

202 weight, and gonad weight for urchins fed Rhodymenia were at least $40 \%$ lower than those for

203 Chondracanthus, Macrocystis (monospecific), and mixed diets each case. Furthermore Leighton

204 (1968) found test growth and gonad index were lower in purple sea urchins fed Rhodymenia than

205 those fed either Macrocystis or Pterygophora. While our results with respect to urchins fed

206 Rhodymenia should be interpreted cautiously, they suggest it is likely poor forage for purple sea

207 urchins.

208 Like many organisms urchins display a trade-off in allocating resources to somatic vs.

209 gonadal growth (Lawrence \& Lane 1982; Steinberg \& van Altena 1992). Our findings pertaining

210 to the performance of urchins fed Pteryoghora are consistent with those of Leighton (1968)-

211 purple sea urchins fed Pterygophora produced relatively large gonads and grew slowly during

212 periods leading up to the peak spawning season. Leighton (1968), however, showed evidence that

213 somatic growth may increase as a proportion of total growth during the time period after

214 spawning, highlighting that the effects of diet may vary with time of year among other factors.

215 Additionally, concerning the jaw growth of urchins fed Pterygophora, Ebert (1980) and Levitan

216 (1991) related increased jaw size and decreased test size to lower food availability in two species

217 of Diadema, suggesting resource allocation toward jaw growth facilitated food gathering ability.

218 The fact that sea urchins in our experiment fed Pterygophora exhibited relatively high jaw

219 growth relative to test growth provides preliminary evidence of a similar phenomenon in $S$.

220 purpuratus. While the urchins in our experiment were not food limited, (as in Ebert (1980a) and

221 Levitan (1991)), it seems possible that some effect of a Pterygophora diet could have triggered a 
222 similar mechanism as that by which food limitation caused resource allocation toward jaws in

223 Diadema.

$224 \mathrm{C}: \mathrm{N}$ ratio, used in our study as a rough measure of algal nitrogen and therefore protein

225 content, was not correlated to any of the performance measures, as Chondracanthus and

226 Macrocystis, which produced similar urchin performance had dissimilar C:N ratios (12.6 and 8.7,

227 respectively, where the range of $\mathrm{C}: \mathrm{N}$ values for all species was $7.4-15.6)$, suggesting that

228 additional factors affected urchin performance. Leighton (1968) found that absorption efficiency

229 was higher for purple sea urchins fed Macrocystis (70\%) than Pterygophora $(50 \%)$ or

230 Rhodymenia (34\%), and that protein and carbohydrates were absorbed more efficiently with

231 Macrocystis than with Pterygophora. These results may explain some of the differences that we

232 observed in performance as a function of diet. Concentrations of fatty acids, minerals

233 Khotimchenko, Vaskovsky \& Titlyanova 2002) and chemical deterrents (Hall et al. 1973; Crews

234 \& Kho-Wiseman 1977; Estes \& Steinberg 1988; Iken \& Dubois 2006) also vary in other algae

235 that are encountered by purple sea urchins and may play a role in nutritional quality, urchin food

236 preference and consumption rates. Additional work is needed to uncover the relative

237 contributions of different factors that may have led to the differences in consumption and

238 performance that we observed.

239 We acknowledge that the sea urchins used in our experiment were collected from a single

240 site, and the barren conditions present there suggest that the urchins had low food availability for

241 some time prior to the experiment. Consumer history has been shown to influence urchin somatic

242 and gonad growth (Livore \& Connell 2012, Williamson \& Steinberg 2012), and the proportion of

243 time food is available has been shown to affect their grazing, growth and resource allocation

244 (Spirlet et al. 1998). Thus, our results could have been affected by the prior history of the

245 individual urchins used in our experiment. However Leighton (1966) found that purple urchins'

246 food preferences did not vary among groups of individuals collected from a variety of habitats. 
247 This coupled with the fact that Leighton (1968) observed the same rankings among Macrocystis,

248 Pterygophora, and Rhodymenia in terms of promoting gonadal growth, and similar differences in

249 allocations to somatic and gonadal growth in sea urchins fed Pterygophora, suggests that our

250 results are generally applicable to purple sea urchins.

251 S. purpuratus and the four algae we tested co-occur only along the west coast of North

252 America (Watanabe 2010). Nonetheless, strong preferences among algae, as well as marked

253 effects of algal nutritional value in terms of fostering growth and reproduction in sea urchins have

254 been noted in temperate and tropical systems around the world, including Lytechinus variegatus

255 in the Gulf of Mexico (Beddingfield \& McClintock 1998), Strongylocentrotus droebachiensis in

256 the Northwestern Atlantic (Larson, Vadas \& Keser 1980), Centrostephanus rodgersii and

257 Tripneustes gratilla in Australia (Steinberg \& van Altena 1992), Paracentrotus lividus in the

258 Mediterranean and eastern Atlantic (Boudouresque \& Verlaque 2007), and various species of

259 Diadema throughout the tropical Indo-Pacific (Muthiga \& McLanahan 2007). Such effects likely

260 play a role in the overall consequences of grazing in many systems. For example, the food

261 preferences of Paracentrotus lividus, which favor leafy algae over corallines or seagrasses have

262 been shown to affect algal assemblage composition (Boudouresque \& Verlaque 2007). Likewise,

263 Scheibling and Anthony (2001) suggested that Strongylocentrotus droebachiensis' preference for

264 local brown algae over the invasive alga Codium fragile may spare patches largely composed of

265 this alga that would otherwise be denuded under barren-forming conditions.

266 Our results focus on the four species of algae that collectively comprised $>75 \%$ of the

267 biomass in kelp forests off Santa Barbara (Miller, Harrer \& Reed 2012) and elucidate the effects

268 of these algae on performance of purple sea urchins, which may have implications for urchin

269 populations in the wild. First, the ability to switch between diets, namely diets of

270 Chondracanthus and Macrocystis (the urchin's preferred food), with little or no cost to growth

271 and reproduction suggests that Chondracanthus could serve as an important alternative food 
272 source when Macrocystis is disproportionately removed by large waves (Dayton \& Tegner 1984;

273 Dayton et al. 1999; Gaylord, Denny \& Koehl 2008). Upon the removal of Macrocystis,

274 understory algae such as Chondracanthus become more abundant (Arkema, Reed \& Schroeter

275 2009; Miller, Reed \& Brzezinski 2011) and may serve as a suitable food that can sustain urchin

276 populations and promote high growth and reproduction. Chondracanthus 'relatively low rate of

277 primary production (Miller, Harrer \& Reed 2012), however, indicates it might not be a long-term

278 sustainable food source. Additionally our results suggest that in the context of the four abundant

279 algae we tested, algal assemblage diversity may not be as important as the availability of one or

280 two high quality food sources. We saw little evidence of a diversity effect; in mixed diets urchins

281 mostly consumed Macrocystis, and performed no differently than had they consumed

282 Macrocystis alone.

283 Urchin preferences among these algae may also have implications for subtidal community

284 structure, and more work is needed to better understand relative consumption rates of these

285 dominant algae in nature (and the factors affecting these relative consumption rates, such as

286 ambient oceanographic conditions and community interactions). Considering the model of

287 urchin-algal dynamics presented by Harrold \& Reed (1985), where following the disappearance

288 of Macrocystis urchins shift their behavior from occupying protected cracks and crevices while

289 consuming drift Macrocystis to actively grazing the understory on the open substratum, the

290 relative availability of the algae tested here could influence the extent of grazing that occurs after

291 such shifts. Our experiment suggests that algal assemblage composition, along with total

292 abundance and urchin density, all may play a role in shifting urchin dynamics in the wake of

293 environmental perturbations to subtidal systems. More work is needed to understand whether

294 these differences in diet translate to differences in urchin populations at the local and regional

295 scale in pre- and post-disturbance temperate rocky reefs. 
296 Acknowledgements

297

298

299

300

301

302

303

304

305

306

307

308

309

310

311

312

313

314

315

316

317

318

319

320

321

322

323

324

325

326

327

328

329

330

331

332

333
Clint Nelson and Shannon Harrer assisted with field collections, and the efforts of many

undergraduate workers were indispensable for data collection. Scott Simon and Christoph Pierre

provided valuable advice on seawater flow-through setup. Robert Miller and Stephen Schroeter

engaged us in many insightful discussions, and William Stockton offered advice on statistical

analysis.

\section{References}

Arkema KK, Reed DC, Schroeter SC. 2009. Direct and indirect effects of giant kelp determine benthic community structure and dynamics. Ecology 90:3126-3137.

Beddingfield SD, McClintock JB. 1998. Differential survivorship, reproduction, growth and nutrient allocation in the regular echinoid Lytechinus variegatus (Lamarck) fed natural diets. Journal of Experimental Marine Biology and Ecology 226:195-215.

Benjamini Y, Hochberg Y. 2000. On the Adaptive Control of the False Discovery Rate in Multiple Testing With Independent Statistics. Journal of Educational and Behavioral Statistics 25:60-83.

Boudouresque CF, Verlaque M. 2007. Ecology of Paracentrotus lividus. In: Lawrence JM, ed. Edible sea urchins: biology and ecology. Elseiver Science B.V. 243-285.

Byrnes JE, Cardinale BJ, Reed DC. 2013. Interactions between sea urchin grazing and prey diversity on temperate rocky reef communities. Ecology 94:1636-1646.

Cavanaugh KC, Siegel DA, Reed DC, Dennison PE. 2011. Environmental controls of giant kelp biomass in the Santa Barbara Channel. Marine Ecology Progress Series 429:1-17.

Crews P, Kho-Wiseman E. 1977. Acyclic polyhalogenated monoterpenes from the red algae Plocamium violaceum. Journal of Organic Chemistry 42:2812-2815.

Dayton PK. 1985. Ecology of kelp communities. Annual Review of Ecology and Systematics 16:215-245.

Dayton PK, Tegner MJ (1984) Catastrophic storms, El Niño and patch stability in a southern California kelp community. Science 224:283-285. 
334

335

336

337

338

339

340

341

342

343

344

345

346

347

348

349

350

351

352

353

354

355

356

357

358

359

360

361

362

363

364

365

366

367

368

369

370

371

372

373

374

375

376

377

378

379

380

381

382

Dayton, PK, Tegner MJ, Edwards PB, and Riser KL. 1999. Temporal and spatial scales of kelp: the role of oceanographic climate. Ecological Monographs 69:219-250.

Ebeling AW, Laur DR, Rowley RJ. 1985. Severe storm disturbances and the reversal of community structure in a southern California kelp forest. Marine Biology 84:287-294.

Ebert TA. 1968. Growth Rates of the Sea Urchin Strongylocentrotus Purpuratus Related to Food Availability and Spine Abrasion. Ecology 49:1075-1091.

Ebert TA. 1977. An experimental analysis of sea urchin dynamics and community interactions on a rock jetty. Journal of Experimental Marine Biology and Ecology. 27:1-22.

Ebert TA. 1980a. Relative growth of sea urchin jaws: an example of plastic resource allocation. Bulletin of Marine Science 30:467-474.

Ebert TA. 1980b. Estimating parameters in a flexible growth equation, the Richards function. Canadian Journal of Fisheries and Aquatic Sciences 37:687-692.

Ebert TA. 1982. Longevity, life history, and relative body wall size in sea urchins. Ecological Monographs 52:353-394.

Estes JA, Steinberg PD. 1988. Predation, herbivory, and kelp evolution. Paleobiology 14:19-36.

Fernandez C, Boudouresque CF. 1998. Evaluating artificial diets for small Paracentrotus lividus (Echinodermata: Echinoidea). In: Mooi R, Telford M, ed. Echinoderms. San Francisco: Proceedings, $9^{\text {th }}$ International Echinoderm Conference. Rotterdam: A.A. Balkema, 651657.

Fernandez C, Pergent G. 1998. Effect of different formulated diets and rearing conditions on growth parameters in the sea urchin Paracentrotus lividus. Journal of Shellfish Research 17:1571-1581.

Gaylord B, Denny MW, Koehl MAR. 2008. Flow forces on seaweeds: field evidence for roles of wave impingement and organism inertia. Biological Bulletin 215:295-308.

Gelman A, Hill J. 2006. Data Analysis Using Regression and Multilevel/Hierarchical Models. Cambridge University Press.

Hall SS, Faulkner DJ, Fayos J, Clardy J. 1973. Oppositol, a brominated sesquiterpene alcohol of a new skeletal class from the red alga; Laurencia subopposita. Journal of the American Chemical Society 95:7187-7189.

Harrold C, Reed DC. 1985. Food availability, sea urchin grazing, and kelp forest community structure. Ecology 66:1160-1169.

Hothorn T, Bretz F, Westfall P. 2008. Simultaneous inference in general parametric models. Biometrical Journal 50:346-363.

Iken K, Dubois A. 2006. Kelp-grazer interactions in Kachemak Bay, Alaska: grazing 
activity and chemical defenses and resource allocation in selected kelp species. Final Report 407. North Pacific Research Board, Anchorage Alaska, USA.

Kenner MC. 1992. Population dynamics of the sea urchin Strongylocentrotus purpuratus in a Central California kelp forest: recruitment, mortality, growth, and diet. Marine Biology 112:107-118.

Khotimchenko SV, Vaskovsky VE, Titlyanova TV. 2002. Fatty acids of marine algae from the Pacific coast of North California. Botanica Marina 45:17-22.

Knip DM, Scheibling RE. 2007. Invertebrate fauna associated with kelp enhances reproductive output of the green sea urchin Strongylocentrotus droebachiensis. Journal of Experimental Marine Biology and Ecology 351:150-159.

Lawrence JM. 1975. On the relationships between marine plants and sea urchins. Oceanography and Marine Biology Annual Review 13:213-286.

Lawrence JM, Lane EM. 1982. The utilization of nutrients by postmetamorphic echinoderms. In: Jangoux M, Lawrence JM, ed. Echinoderm nutrition. Rotterdam: A.A. Balkema, 331-371.

Leighton DL. 1968. A comparative study of food selection and nutrition in the abalone Haliotis rufescens (Swainson), and the sea urchin Strongylocentrotus purpuratus (Stimpson). D. Phil. Thesis, University of California, San Diego, CA.

Leighton DL. 1971. Grazing activities of benthic invertebrates in Southern California kelp beds. Nova Hedwigia 32:421-453.

Levitan DR. 1991. Skeletal changes in the test and jaws of the sea urchin Diadema antillarum in response to food limitation. Marine Biology 111:431-435.

Miller RJ, Harrer SL, Reed DC. 2012. Addition of species abundance and performance predicts community primary production of macroalgae. Oecologia 168:797-806.

Miller RJ, Reed DC, Brzezinski MA. 2011. Partitioning of primary production among giant kelp (Macrocystis pyrifera), understory macroalgae, and phytoplankton on a temperate reef. Limnology and Oceanography 56:119-132.

Muthiga NA, McClanahan TR. 2007. Ecology of Diadema. In: Lawrence JM, ed. Edible sea urchins: biology and ecology. Elseiver Science B.V. 205-225.

North WJ, Pearse JS. 1970. Sea urchin population explosion in Southern California coastal waters. Science 167:209.

Pennings SC, Nadeau MT, Paul VJ. 1993. Selectivity and growth of the generalist herbivore Dolabella auricularia feeding upon complementary resources. Ecology 74:879-890.

Pinheiro J, Bates D, DebRoy S, Sarkar D, R Development Core Team. 2012. nlme: Linear and Nonlinear Mixed Effects Models. R package version 3.1-103. 
432

433

434

435

436

437

438

439

440

441

442

443

444

445

446

447

448

449

450

451

452

453

454

455

456
R Development Core Team. 2012. R: A language and environment for statistical computing. $R$ Foundation for Statistical Computing, Vienna, Austria. ISBN 3-900051-07-0, URL http://www.R-project.org/.

Reed DC, Rassweiler A, Arkema KK. 2008. Biomass rather than growth rate determines variation in net primary production by giant kelp. Ecology 89:2493-2505.

Reed DC, Rassweiler A, Carr MH, Cavanaugh KC, Malone DP,Siegel DA. 2011. Wave disturbance overwhelms top-down and bottom-up control of primary production in California kelp forests. Ecology 92:2108-2116.

Russell MP. 1987. Life history traits and resource allocation in the purple sea urchin, Strongylocentrotus purpuratus (Stimpson). Journal of Experimental Marine Biology and Ecology 108:199-216.

Steinberg PD, van Altena I. 1992. Tolerance of marine invertebrate herbivores to brown algal phlorotannins in temperate Australasia. Ecological Monographs 62:189-222.

Vadas RL, Beal B, Dowling T, Fegley JC. 2000. Experimental field tests of natural algal diets on gonad index and quality in the green sea urchin, Strongylocentrotus droebachiensis: a case for rapid summer production in post-spawned animals. Aquaculture 182:115-135.

Watanabe JM. 2010. SeaNet: Common Marine Organisms of Monterey Bay, California. Available at http://seanet.stanford.edu/index.html\#kelp_forest (accessed 07 December 2014). 
1

Performance Measures

Bars represent mean ( $\pm 1 \mathrm{SE}$ ) for (a) change in test diameter, (b) change in wet weight, (c) gonad dry weight, and (d) change in jaw length, over the course of the experiment. Letters indicate groups of means as determined by post-hoc general linear hypothesis tests with different letters signifying means that are different at the $p<0.05$ level. 
(a)

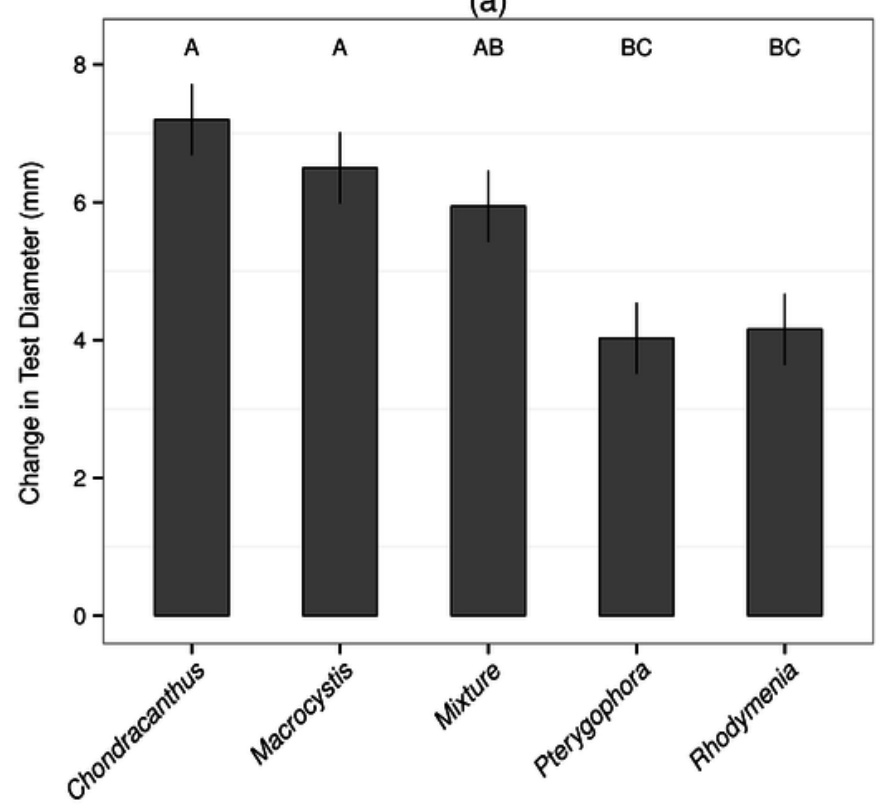

(c)

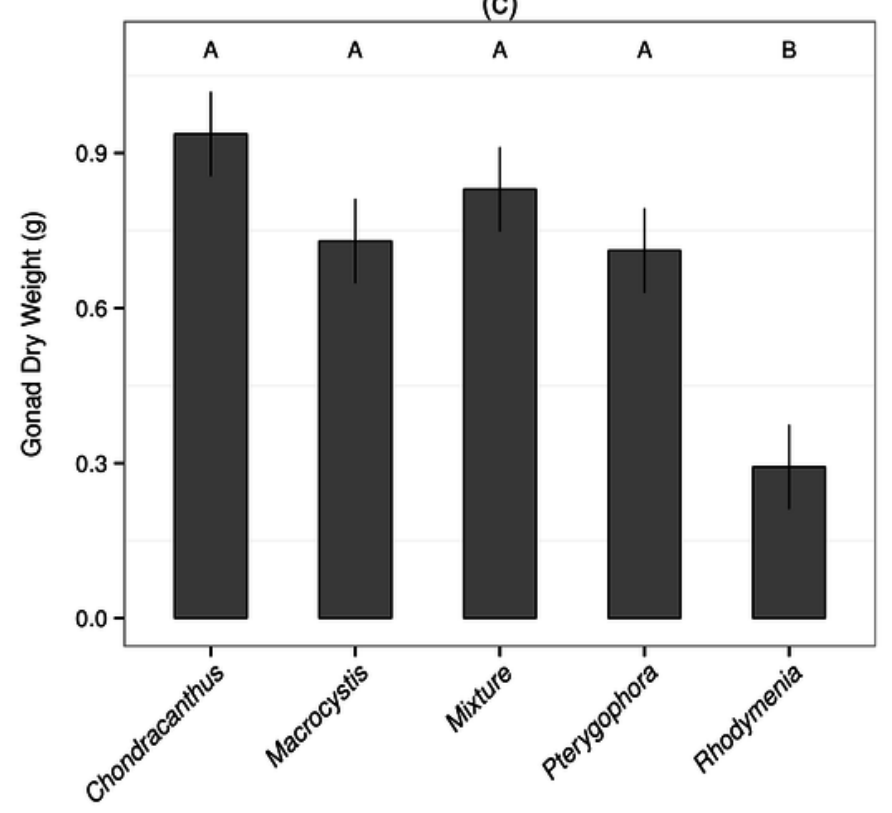

(b)

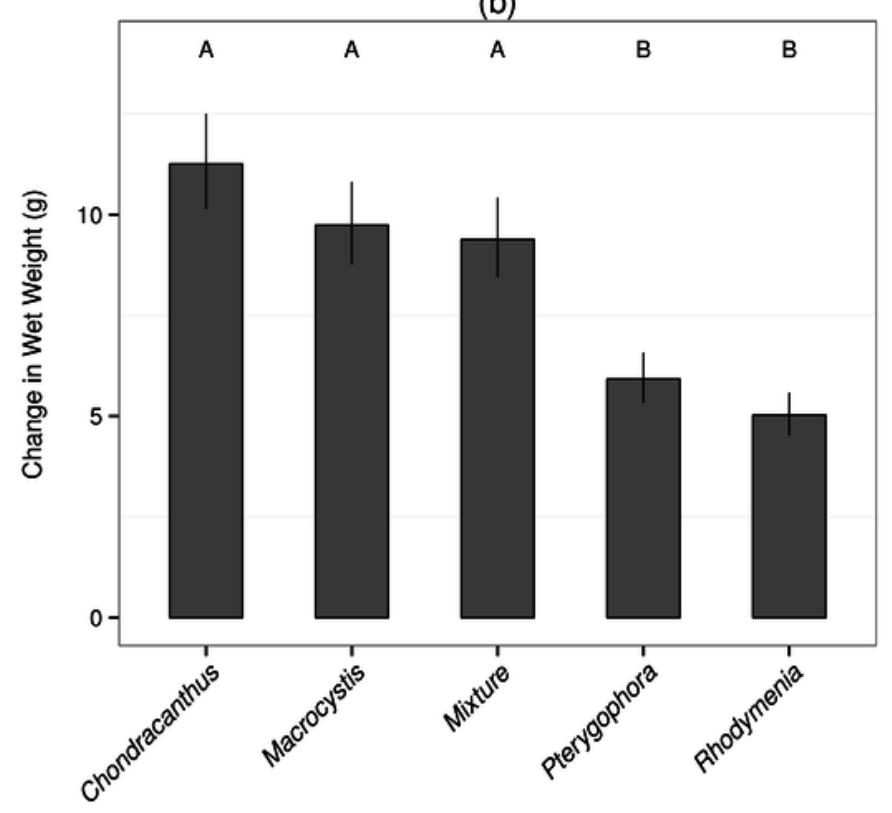

(d)

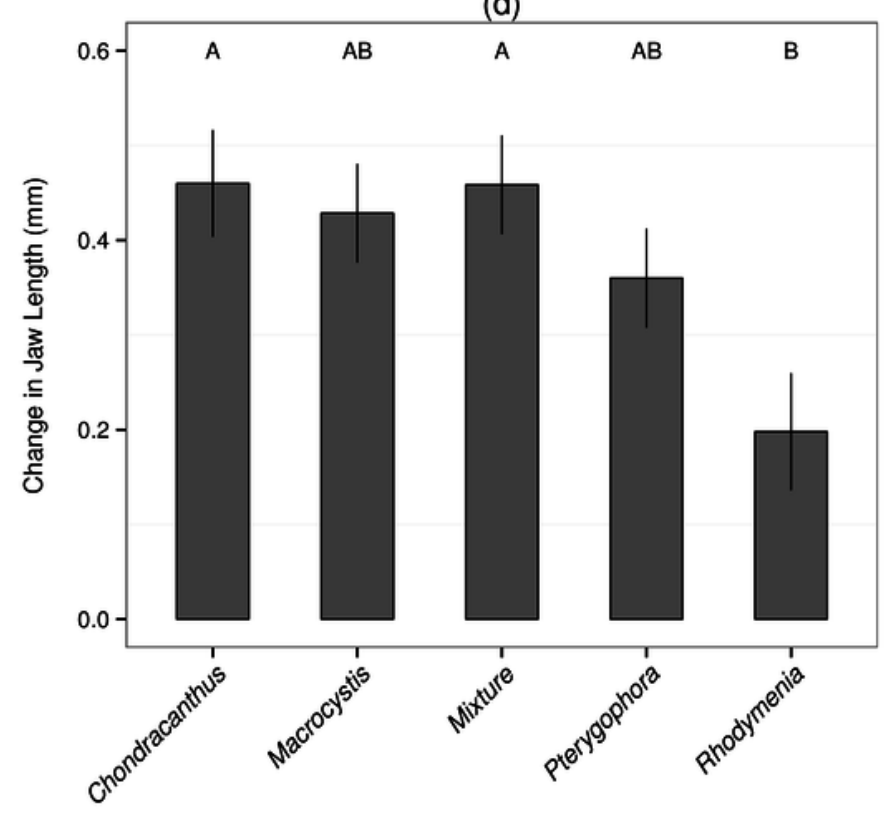


Table $\mathbf{1}$ (on next page)

Performance and Consumption Across Diets

F-tables for linear models fit with different aspects of urchin performance as response variables and diet as a fixed factor. 


\begin{tabular}{crrrrrr} 
& & $\boldsymbol{d f}$ & $\boldsymbol{S S}$ & $\boldsymbol{M S}$ & $\boldsymbol{F}$ & $\boldsymbol{P r}(>\boldsymbol{F})$ \\
\hline \hline \multirow{2}{*}{ Change in Test Diameter } & Diet & 4 & 56.2 & 14.1 & 7.52 & $<0.001$ \\
& Residual Error & 30 & 56.0 & 1.87 & & \\
\hline \multirow{2}{*}{ Change in Wet Weight } & Diet & 4 & 0.642 & 0.160 & 11.1 & $<0.001$ \\
& Residual Error & 30 & 0.434 & 0.014 & & \\
\hline \multirow{2}{*}{ Gonad Dry Weight } & Diet & 4 & 1.68 & 0.420 & 8.99 & $<0.001$ \\
& Residual Error & 30 & 1.40 & 0.047 & & 0.021 \\
\hline \multirow{2}{*}{ Change in Jaw Length } & Diet & 4 & 0.263 & 0.066 & 3.44 & $<0.001$ \\
& Residual Error & 27 & 0.516 & 0.019 & & \\
\hline \multirow{2}{*}{ Consumption Rate } & Diet & 4 & 0.559 & 0.140 & 19.1 & $<$ \\
& Residual Error & 30 & 0.220 & 0.007 & & \\
\hline
\end{tabular}


2

Consumption Rate

Bars represent mean consumption rate $( \pm 1 \mathrm{SE}$ ) averaged over the experiment. Letters indicate groups of means as determined by post-hoc general linear hypothesis tests with different letters signifying means that are different at the $p<0.05$ level. (a) Consumption rate of the different algal species in the mixed diet. (b) Consumption rate of all diets. 
(a)

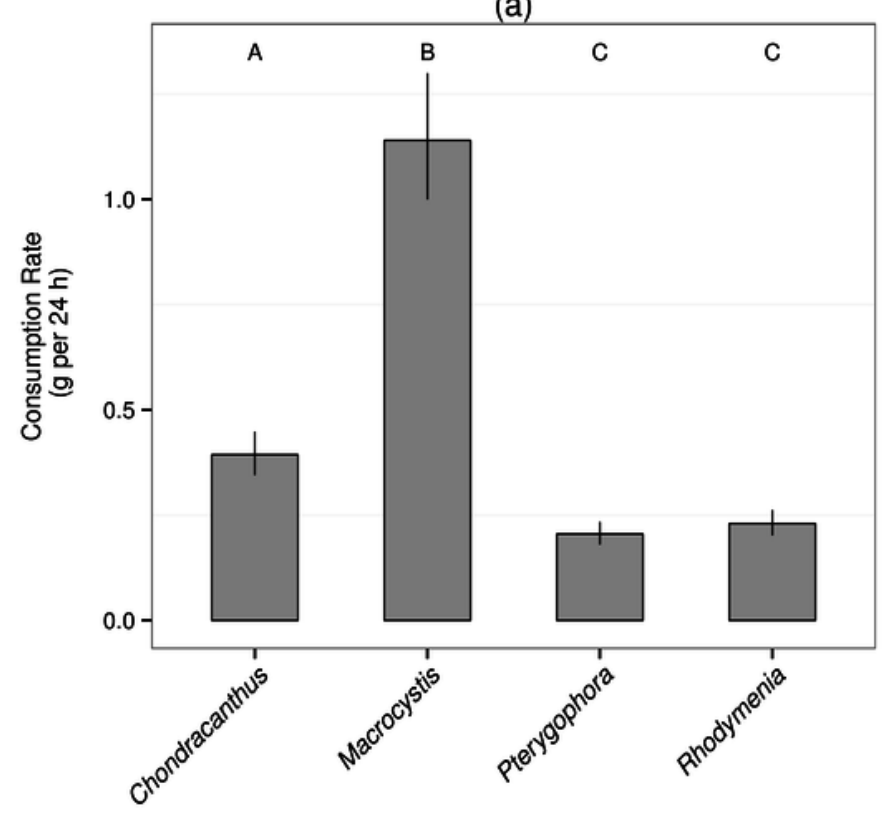

(b)

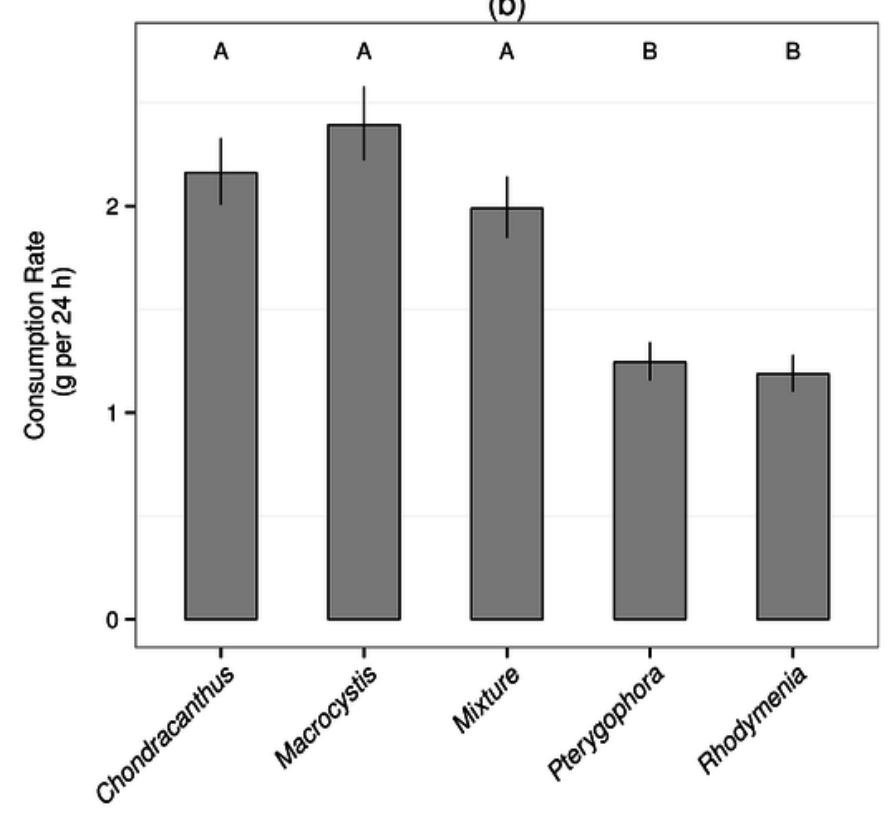


Table 2 (on next page)

Consumption Rate within the Mixed Diet

F-table for a linear model fit with consumption rate as the response variable, algal species as a fixed factor and urchin container included as a random effect. 


\begin{tabular}{|c|c|c|c|c|c|}
\hline & & $\begin{array}{r}d f \\
\text { (numerator) }\end{array}$ & $\begin{array}{r}d f \\
\text { (denominator) }\end{array}$ & $\boldsymbol{F}$ & $\operatorname{Pr}(>F)$ \\
\hline \multirow[t]{2}{*}{ Fixed Effects } & Species & 4 & 18 & 80.7 & $<0.001$ \\
\hline & & $\begin{array}{c}\text { Standard } \\
\text { Deviation }\end{array}$ & & & \\
\hline \multirow[t]{2}{*}{ Random Effects } & Container & $1.05 \times 10^{-5}$ & & & \\
\hline & idual Error & 0.150 & & & \\
\hline
\end{tabular}




\section{3}

\section{Algal C:N}

Each path corresponds to a different a algal species (indicated on right), passing through the mean carbon:nitrogen ratio $(\mathrm{C}: \mathrm{N})$ calculated for each collection date. Individual points represent C: $N$ values obtained for each species on each collection date $(n=2)$.

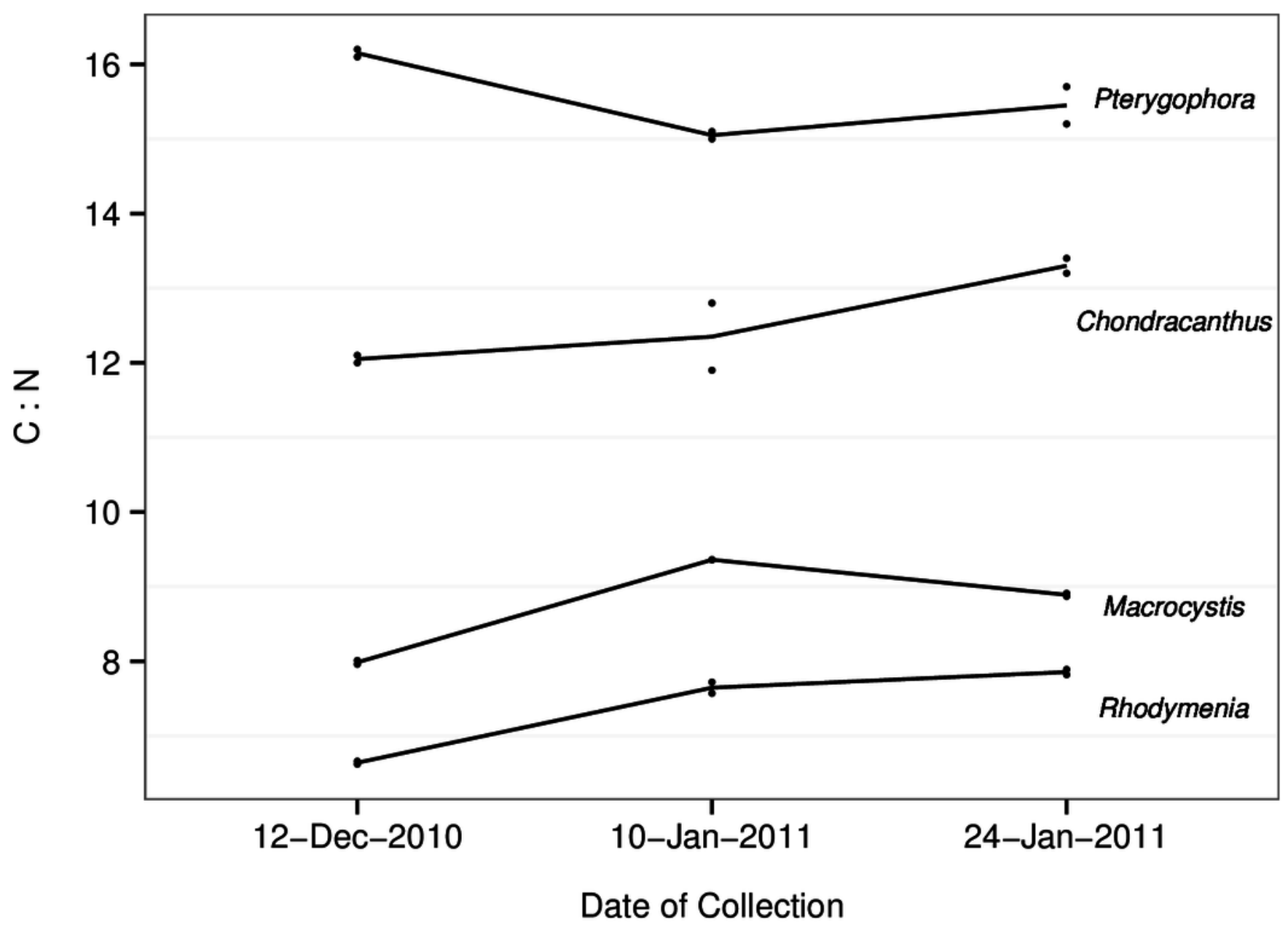

